\title{
Temas médico-sociais e a intervenção em saúde: a violência contra mulheres no discurso dos profissionais
}

\author{
Social medical themes and the health intervention: \\ violence against women in the professional's discourse
}

Lígia Bittencourt Kiss ${ }^{1}$ Lilia Blima Schraiber ${ }^{1}$
${ }^{1}$ Departamento de Medicina Preventiva, Faculdade de Medicina, Universidade de São Paulo. Av. Dr. Arnaldo $455,2^{\circ}$ andar, sala 2170 , Cerqueira César. 01246-903 São Paulo SP. ligia.Kiss@lshtm.ac.uk
Abstract This study deals with violence against women as a health care matter. It was part of a research in public services of São Paulo (Brazil), including the prevalence of violence among users from 15 to 49 years old; the study of their medical records; the description of the services; and interview with 50 professionals, focusing the routine and the ideals of health work, the perception on the existence of violence cases, the offer of assistance or its obstacles and the representations on violence. This article analyses the content of the professional narratives and uses the other data to characterise the assistance context. Confirming the literature, violence was almost always regarded as a relevant problem but outside the professional's intervention boundaries. Isolated actions and in a personal basis were reported. Fear and professional impotence were mentioned, but none positive aspect for potential interventions. The professionals showed lack of knowledge of specialized reference services. In conclusion, the difficulties in the acceptance of violence cases should be worked in three dimensions: the narrow definition of professionals' competence that excludes violence as an object; the absence of technological definitions for professional actions; and effective support in their services.

Key words Violence against women, Health work, Gender and health, Violence and health
Resumo Estuda-se a violência contra mulheres como alvo dos cuidados em saúde. É parte de pesquisa em serviços públicos em São Paulo, envolvendo prevalência de casos entre usuárias de 15 a 49 anos; estudo de seus prontuários; descrição dos serviços, por sua observação; e entrevistas semiestruturadas com 50 de seus profissionais, acerca da rotina e do ideal de trabalho em saúde, percepções quanto à existência de casos, ofertas assistenciais ou seus obstáculos e representações sobre violência. Analisa-se o conteúdo das narrativas profissionais, usando-se os demais dados para caracterização de seus contextos assistenciais. Reiterando a literatura, violência foi quase sempre tida como problema relevante, mas fora dos escopos das intervenções profissionais. Relataram-se ações isoladas e em caráter pessoal. Medos e impotência profissional foram mencionados, mas nenhum aspecto positivo para eventual intervenção. Os profissionais mostraram parco conhecimento de serviços especializados de referência. Conclui-se que as dificuldades na aceitação de casos de violência deveriam ser trabalhadas em três dimensões: a estreita definição da competência profissional, excluindo a violência como objeto; a indefinição tecnológica do fazer profissional; e a ausência de apoios efetivos em seus serviços.

Palavras-chave Violência contra a mulher, Trabalho em saúde, Gênero e saúde, Violência e saúde 


\section{Introdução: a violência contra mulheres como questão de saúde}

Muitos têm sido os esforços para que a atenção curativa e preventiva a mulheres em situação de violência faça parte dos programas assistenciais em saúde. Desde a década de 1980, o movimento feminista busca efetivar medidas de combate ao problema ${ }^{1}$. Em suas políticas governamentais, o Brasil firmou compromissos para que essa violência seja tratada no quadro dos Direitos $\mathrm{Hu}$ manos, garantindo-se a cidadania e a promoção da equidade de gênero, conforme as conferências e os tratados internacionais ratificados pelo país ${ }^{2}$.

Nos anos 1990, a violência contra mulheres entra na pauta de propostas do campo da saúde. Em 1996, a Organização Mundial da Saúde (OMS) reconheceu a violência contra mulheres como um problema mundial de saúde pública ${ }^{3}$. No Brasil, desde 1989, com a criação do primeiro serviço de atendimento a mulheres vítimas de violência sexual, passa-se a priorizar a normatização da assistência e projetos estaduais e municipais de ampliação das redes de atendimento ${ }^{4}$.

Contudo, no cotidiano dos serviços de saúde a incorporação da temática mostra-se discreta e reticente. O compromisso assumido por instâncias políticas parece não atingir diretamente o trabalho dos agentes concretos da prática em saúde. Estudos internacionais apontam como barreiras nessa direção: a resistência à revelação da situação pela mulher; preconceitos (de classe, raça, sexismo, de idade, homofobia) ou valores éticos e culturais que desvalorizam a questão para a assistência; a falta de conhecimento do profissional sobre o tema; o despreparo do profissional; a falta de tempo; ausência de controle quanto aos resultados da intervenção; desconhecimento ou a efetiva ausência de redes de atendimento que possam ser referências específicas ${ }^{5-14}$. A elas acrescentaríamos a racionalidade técnico-científica que embasa as práticas e o trabalho profissional como um obstáculo de ordem epistemológica $^{15-17}$ na abordagem de temas cuja natureza remete de imediato à sociabilidade, à cultura e ao emocional-afetivo. Esta questão, que se aplica ao estudo da violência em geral, exacerba-se no caso das violências associadas às relações de intimidade, tal como a violência de gênero ${ }^{4}$.

Esse conjunto de barreiras constitui uma base simbólica e material de desafios de ordem prática, que podem explicar os descompassos entre as intenções políticas e o agir profissional concreto. A própria OMS reconhece distâncias e mesmo divergências entre as propostas gover- namentais e a realidade do cotidiano assistencial. Um dos fatores-chave no aparente fracasso na efetivação dessas propostas seria a incapacidade de integrar a perspectiva de gênero e a promoção dos direitos como prioridades no planejamento e na implementação das atividades de assistência e intervenção, com repercussões efetivas no agir profissional. Quando ocorrem, as investidas nesse sentido são de pouco impacto ${ }^{3}$.

O presente estudo buscou explorar essas questões. Pesquisou-se, de um lado, ante as prevalências de violência contra mulheres entre usuárias de serviços de saúde, a percepção e representações de seus profissionais acerca desse problema. De outro, os obstáculos ao acolhimento de casos nas atuais condições do trabalho e diante das posturas derivadas daquelas representações.

\section{Desenho do estudo}

O estudo com profissionais foi parte de pesquisa maior desenvolvida em serviços de saúde da rede pública (Sistema Único de Saúde/SUS) da Grande São Paulo, Brasil. O desenho geral contemplou cinco braços de investigação, quatro dos quais aqui explorados: caracterização dos serviços em termos de seu cotidiano assistencial; estudo de prevalência de violência contra a mulher entre suas usuárias; levantamento do perfil de demanda e atendimento dessas usuárias; estudo das percepções dos profissionais quanto à existência de casos de violência contra mulheres e suas representações como questão social e de saúde.

Com vistas a conhecer o cotidiano assistencial dos serviços, os participantes da pesquisa foram alvo de observação do tipo etnográfico sobre suas formas de organizar a assistência e seus funcionamentos no dia a dia, o que se complementou com levantamento de dados documentais. A pesquisa de casos entre as usuárias foi feita pela estimativa de prevalência para distintos tipos de violência e agressores, aplicando-se questionário a mulheres de 15 a 49 anos. O perfil da demanda e dos atendimentos foi feito por leitura dos prontuários dessas entrevistadas.

Uma apresentação mais detalhada desse desenho e metodologia do estudo encontra-se em outra publicação ${ }^{18}$. Neste artigo, voltado para o estudo com os profissionais desses serviços, utilizou-se parte desses outros dados, pois fornecem informações sobre o contexto de trabalho em que os profissionais se inserem, uma das bases para a interpretação e compreensão de suas percepções e representações acerca da violência. 


\section{Amostras}

A amostra de serviços foi intencional, garantindo-se boa distribuição geográfica (regiões de saúde norte, sul, leste e centro-oeste) das unidades do município de São Paulo. Foram investigados 19 serviços, 14 no município de São Paulo e cinco em outros três municípios da Grande São Paulo. O conjunto foi agrupado em nove sítios de pesquisa. A seleção baseou-se em critérios de viabilidade da pesquisa e de posterior implantação de protocolos de atendimento, desenvolvidos com base na própria investigação. A amostra de usuárias foi do tipo consecutivo por ordem de chegada ao serviço ${ }^{18}$, sendo a de prontuários composta apenas pelos prontuários dessas entrevistadas.

Quanto ao estudo dos profissionais, definiuse o mínimo de três para cada serviço, a fim de diversificar as áreas de atuação, devendo o profissional ser trabalhador regular dele. O convite para participar foi realizado diretamente pela entrevistadora, a partir de uma primeira indicação da direção do serviço.

\section{Técnicas de coleta de dados e instrumentos}

Para a caracterização dos serviços, foram colhidos dados de produção (volume médio mensal de atendimento nos últimos anos) e número de profissionais das equipes de trabalho, bem como as áreas de atuação. Foram ainda feitas anotações da observação direta da produção assistencial em caderno de campo, estimulando-se a descrição densa de uma semana usual de funcionamento. A descrição valorizou a dinâmica do serviço por período do dia e dia da semana, anotando todas as atividades existentes e sua sequência em fluxograma assistencial. Também se examinou o acesso aos prontuários e outros registros, além da qualidade deles.

O estudo das prevalências valeu-se de experiência anterior com questionário usado em um estudo multipaíses do qual participou o Brasil ${ }^{19}$. Já os prontuários foram lidos mediante fichas padronizadas, levantando-se queixas, diagnósticos, tratamentos e encaminhamentos por tipo de atendimento, além do registro de violência.

O estudo com os profissionais foi realizado com entrevistas semiestruturadas, gravadas e transcritas. O roteiro das entrevistas abordou a trajetória profissional, o cotidiano do trabalho, a possibilidade de atendimento a casos de violência contra a mulher, a percepção sobre a questão e o conhecimento de rede intersetorial de ser- viços especializados no atendimento a mulheres vítimas de violência na sua região e na Grande São Paulo.

\section{Análise}

Os serviços foram tipificados quanto a: composição da equipe profissional; tipos de atividades assistenciais oferecidas; ser também referência, além de porta de entrada do SUS; modo de captar a clientela (demanda espontânea e/ou busca ativa); volume de atendimento de mulheres de 15 a 49 anos; padronização da informação e do registro em prontuários; identificação do agente do registro e legibilidade dos prontuários.

As prevalências foram estudadas por tipo (físico, sexual e/ou psicológico). Cada tipo foi definido pela resposta positiva aos itens de seu tipo no questionário, independentemente de outras respostas positivas aos demais tipos. Assim, foram considerados tipos exclusivos ou combinados e se ocorreram no último ano relativamente à data da entrevista ou alguma vez na vida, além da frequência dos episódios (uma, poucas ou muitas vezes). Já no caso dos registros em prontuários, foi considerada qualquer anotação existente de violência, discriminando-se o profissional e a atividade assistencial da anotação. Esses dados são tomados como indicadores da visibilidade ou invisibilidade dos casos de violência nos serviços.

Quanto às entrevistas dos profissionais, a primeira análise deu-se por categoria profissional, buscando-se também a atividade assistencial mais frequente de cada categoria: se curativa ou educativa; se mais individual ou grupal; se mais conectada às ações comunitárias ou internas aos serviços. Em seguida, procedeu-se a uma análise transversal entre as diferentes categorias profissionais estudadas, com o objetivo de reconhecer, entre elas, as aproximações e os distanciamentos. Em ambos os casos foi feita uma análise de conteúdo dos discursos ou do tipo temático ${ }^{20}$. Foram identificados núcleos de sentido nas falas dos profissionais que se referiam ao contexto de trabalho e à clientela dos serviços, à violência na sociedade $\mathrm{e}$ à assistência a casos de violência, dificuldades e sentimentos na abordagem de casos.

\section{Ética da pesquisa}

A pesquisa foi aprovada pelo Comitê de Ética da instituição responsável. Todos os participantes, profissionais e usuárias, assinaram termo de consentimento informado, para todas as modalidades de estudos pretendidos. Maior detalha- 
mento das medidas de privacidade e sigilo nas entrevistas, de segurança pessoal e retaguarda assistencial, considerando-se as especificidades do tema, encontra-se em outras publicações ${ }^{18,19}$. A pedido, observou-se o anonimato dos profissionais e de seus respectivos serviços.

\section{Resultados}

\section{Os contextos de trabalho dos profissionais}

Todos os serviços pertenciam ao sistema público de saúde e eram do tipo ambulatorial. A grande maioria (17) constituía atenção básica. Quatro deles (região leste de São Paulo) pertenciam ao Programa Qualis, assistência na modalidade Saúde da Família. Destaca-se nela a presença de agentes comunitários de saúde (ACS), que atuam no interior das unidades, em visitas domiciliares e atividades comunitárias.

Os dois serviços que completam os 19 estudados constituíam contextos especiais de assistência: um combinava um setor de atenção básica com outro de ambulatório referência, mas organizados de modo bastante individualizado e mantendo, ambos, a característica de atendimento clínico generalista e gineco-obstétrico também generalista; o outro serviço, além de constituir ambulatório de referência, era especializado em doenças sexualmente transmissíveis (DST) e HIV/ Aids. Este último possuía equipe multiprofissional mais diversificada que todos os demais. As outras equipes eram compostas, em sua grande maioria, apenas por médicos, enfermeiros e auxiliares de enfermagem. Profissionais como psicólogos e assistentes sociais estavam em apenas sete equipes de trabalho.

As principais especialidades médicas encontradas nas equipes foram: clínicos, ginecologistas e pediatras. As atividades desenvolvidas nestes serviços eram principalmente consultas médicas e atendimentos de enfermagem, que inclui a consulta de enfermagem e atividades em grupo para ações educativas de orientação e prevenção. A saúde reprodutiva e a saúde infantil eram alvos privilegiados das ações individuais ou grupais, destacando-se também os exames preventivos para câncer de colo de útero, grupos de prénatal e de contracepção, além de vacinação e coleta de exames laboratoriais.

Nos quatro serviços de atenção à Saúde da Família, havia demanda ativamente buscada através de rotinas de visitação domiciliar, além de outras atividades comunitárias. Os ACS tinham também a função de apresentar casos relevantes encontrados nessas visitas, em reuniões sistemáticas da equipe do serviço, momento em que emergiam com frequência casos de violência doméstica, contra mulheres e crianças ou adolescentes. Já os demais serviços operavam apenas com demanda espontânea da clientela e ações intraunidades.

Em termos da produção assistencial e produtividade do trabalhador, todos os profissionais estavam subordinados às normas dos serviços públicos de saúde, que estabeleciam como produtividade mínima o critério de realização de uma consulta clínica a cada 15 minutos, em média, considerada a jornada de trabalho completa de 20 horas semanais para os médicos e os demais profissionais. A única exceção foram os médicos dos serviços da Saúde da Família, com jornada de 40 horas semanais.

Os contextos de trabalho formaram um perfil de serviços bastante similares entre si, com equipes pequenas e pouco diversificadas e grande volume de atendimentos. Afora os serviços da Saúde da Família, em geral identificou-se pouca interação com a comunidade, além de atividades assistenciais bastante convencionais, com tímidas tentativas de se articularem ações curativas e preventivas.

Em nenhum dos serviços a atenção a pessoas em situação de violência se apresentou como um problema organizacional da assistência a ser prestada.

\section{O contexto assistencial: prevalências de casos e registros em prontuários}

O total de usuárias em que se aplicou o questionário foi de 3.193 mulheres, encontrando-se 3.051 prontuários. As prevalências estão na Tabela 1. Cada taxa apresentada não é exclusiva, podendo a usuária que relatou um tipo também ter relatado outros. Aliás, a superposição das violências é muito grande ${ }^{18}$. Analisadas no sentido de tipos puros, contudo, a psicológica é a que mais se apresentou na forma exclusiva, seguida da violência física. A violência sexual raramente ocorre sozinha.

Todas as formas de violência apresentam altas magnitudes, mas baixíssimo registro. Apenas 3,8\% dos prontuários de mulheres que relataram algum episódio de qualquer tipo de violência continham registro de violência, anotação que se concentrou na assistência em saúde mental (34\% do total), lembrando-se que nem todos os serviços investigados dispunham dessa ativi- 
Tabela 1. Prevalência de violência ao menos uma vez na vida por agressor e registros de casos em prontuários.

\begin{tabular}{|c|c|c|c|c|c|c|c|}
\hline \multirow{2}{*}{ Variáveis } & \multicolumn{2}{|c|}{$\begin{array}{c}\text { Violência } \\
\text { psicológica }(P)\end{array}$} & \multicolumn{2}{|c|}{$\begin{array}{l}\text { Violência física }(\mathrm{F}) \\
\text { e/ou sexual }(\mathrm{S})\end{array}$} & \multicolumn{2}{|c|}{$\begin{array}{l}\text { Violência } \\
\text { P, F e/ou S }\end{array}$} & \multirow{2}{*}{$\begin{array}{l}\text { Total da } \\
\text { amostra }\end{array}$} \\
\hline & $\%$ & IC 95\% & $\%$ & IC 95\% & $\%$ & IC 95\% & \\
\hline Qualquer agressor & 68,9 & $66,4-71,4$ & 54,8 & $53,1-56,6$ & 76,0 & $74,2-77,8$ & 3.193 \\
\hline Agressores que não o parceiro & 44,8 & $43,0-46,5$ & 25,6 & $24,1-27,1$ & 52,7 & $50,9-54,4$ & 3.193 \\
\hline Parceiro íntimo & 52,9 & $51,1-54,6$ & 45,3 & $43,5-47,1$ & 61,1 & $59,4-62,9$ & $3.089^{* *}$ \\
\hline Registro em prontuário & 2,1 & $1,6-2,7$ & 11,8 & $1,4-2,3$ & 33,1 & $2,5-3,8$ & $3.051^{*}$ \\
\hline
\end{tabular}

“42 prontuários não localizados; ${ }^{* *}$ Mulheres com parceiros alguma vez na vida.

dade. Os registros também não são distribuídos homogeneamente pelos serviços, chamando a atenção o fato de que aqueles que contavam com os agentes comunitários, os quais reportavam casos à unidade, não estão entre os que mais registram a violência ${ }^{18}$.

Nos dados já publicados ${ }^{18}$, observamos a taxa de $62,1 \%$ de casos graves dentre os de violência física alguma vez na vida. Dentre os de física e/ou sexual, temos a taxa de $43,7 \%$ de casos com grande recorrência dos episódios (muitas vezes). Em relação à violência por parceiro íntimo, modalidade que constitui $83 \%$ do tipo físico e/ou sexual por qualquer agressor, destaca-se também uma taxa bastante elevada no último ano (16,4\%; IC95\% 15,1-17,8\%).

O contexto assistencial descrito, portanto, aponta para a existência de muitas usuárias em situações de violência, em sua maioria graves e recorrentes, além de muitos casos de violência atual (no último ano). No entanto, a invisibilidade no registro é a regra.

\section{Os profissionais e seu cotidiano}

Foram obtidas entrevistas com 50 dos 57 profissionais previstos, dentre eles 15 médicos, 13 gerentes, 11 enfermeiros, oito auxiliares de enfermagem e três agentes comunitários. Três das perdas foram em virtude de os profissionais terem participado de oficinas em que se tratou da violência; as quatro restantes por motivos pessoais ou de dificuldades de agenda e não incluíam a violência na recusa. Todos os entrevistados não tiveram nenhum treinamento específico sobre a questão e atuavam em moldes da formação tida nas respectivas áreas de graduação.

\section{O trabalho assistencial na visão dos profissionais}

Apesar de a maioria dos entrevistados reconhecer que há problemas na estruturação dos serviços e nos recursos disponibilizados, os médicos são os que mais o enfatizam. Os principais obstáculos identificados por eles são: demanda excessiva; falta de medicamentos; precariedade das instalações físicas; demora e falta de qualidade dos serviços laboratoriais.

Em diferentes momentos na entrevista e de forma recorrente, os entrevistados apontam a incompatibilidade entre ofertas do serviço e demanda dos usuários. Em suas opiniões os usuários não captam a proposta dos serviços, pois iriam a eles com expectativa de resolução rápida de seus problemas, enquanto a equipe buscaria efetivar uma rotina não só curativa, mas também de prevenção e promoção à saúde. Isso dificultaria a implantação de novos protocolos, inclusive o de atendimento a casos de violência. Particularmente, os médicos alegam perda de motivação profissional e muitos limites para sua atuação, que associam ao grande volume de atendimento e ao perfil dos usuários. Relativamente a este, apontam o tipo de queixas e demandas que apresentam, além das dificuldades de compreensão das orientações por eles fornecidas, sendo esta última visão partilhada com os demais. Segundo o conjunto dos entrevistados, devido à precária condição socioeconômica e cultural, faltaria a esses usuários repertório para entender os objetivos do serviço e as informações que lhe são transmitidas durante o atendimento. Veem como consequência uma baixa adesão do usuário às propostas do serviço, o que provocaria distorções na forma de atuação da unidade básica, pressionada a assumir as funções de pronto-atendimento, com volume intenso de casos. Estes aspectos, somados 
às dificuldades estruturais no serviço e à demanda essencialmente curativa, gerariam dificuldades para que os profissionais promovam mudanças no modelo de atenção.

Eles não conseguem perceber a diferença entre um posto e um pronto-socorro. (Enfermeira)

O serviço propõe melhor qualidade de vida para as pessoas; nem todo mundo aceita essa melhor qualidade de vida. (Agente)

Eu acho que ele entende muito pouco a vida dele, então é confuso você orientar uma pessoas dessas. Não teria muito que fazer. (Médica)

A gerência, que funciona como plano intermediário entre as políticas públicas e os demais profissionais, também encontra dificuldades de implantação de uma racionalidade de trabalho que escape ao convencional, seja incorporando mais ações de prevenção e promoção à saúde, seja acolhendo temas como a violência. Apesar de serem os únicos entrevistados que valorizam o trabalho em equipe, fugindo um pouco do modelo centrado no médico e na consulta individual, as concepções dos gerentes sobre a forma de organização do trabalho e as ações de assistência são bastante pessimistas quanto a possibilidades de mudanças.

Então, você ainda tem uma coisa de estar muito trabalhando a questão da clínica mesmo, da questão da medicalização. E a promoção é uma coisa que a gente... a proposta, né, de todo mundo, a gente ainda está longe de conseguir, né? (Gerente)

Percebe-se que os profissionais valorizam a necessidade de mudança na estruturação e na oferta do serviço; posicionam-se de forma engajada em relação a essas mudanças, mas identificam os obstáculos para tanto na demanda dos usuários. Limites intrínsecos ao perfil da população que atendem e às demandas de saúde dirigidas ao serviço impediriam a transição de um modelo curativo de assistência para um modelo de promoção à saúde.

\section{As percepções dos profissionais acerca da violência}

Apesar de serem homens e mulheres, universitários e não universitários, pertencendo a áreas distintas de atuação, com participação diversa nas atividades da assistência, os depoimentos coletados divergiram pouco entre si no que diz respeito à percepção da violência como questão médico-sanitária. Essa homogeneidade no discurso de diferentes entrevistados (no caso, médicos e enfermeiras) foi também encontrada no México?.
Alguns dos profissionais, sobretudo os da Saúde da Família, dizem ter notícias de situações em suas comunidades. Há, porém, uma grande distância, segundo eles, entre tomar conhecimento das situações e reconhecê-las como atinentes à assistência e, ainda mais, intervir.

Os depoimentos dos profissionais reiteram a invisibilidade da violência nos serviços, sugerindo que não investigam casos no cotidiano assistencial. Alegam para tanto muitas dificuldades, entre elas o silêncio da própria mulher, aspecto também verificado por Angulo-Tuesta ${ }^{21}$.

Mas o silêncio é visto como um problema só da mulher e não remetido para a responsabilidade também do profissional. Em seus relatos, a tentativa de obter uma espécie de "confissão" seria tão trabalhosa que se tornaria um grande problema, ou seria, de vez, inviável no seu contexto de trabalho. Ademais, a natureza doméstica e privada da violência contra mulheres contribui para recusá-la como alvo assistencial.

A gente tem que arrancar das pessoas essas coisas [...] porque não se fala, assim, normalmente, né? (Médico)

É difícil abordar. Eles têm medo ou têm vergonha ou não querem se expor. Então é difícil entrar nesses detalhes com a família. (Agente)

Em seu conjunto, os entrevistados adotam a posição de que a violência contra mulheres é uma questão socialmente importante, embora não seja por eles identificada como parte de seu particular trabalho.

Não tenho conhecimento, não tenho ideia de como a saúde pode atuar, a não ser em relação a fazer [...] o exame de corpo delito, esse tipo de coisa [...] e fazer a captação da denúncia. (Médico)

A saúde, eu acho que não [tem um papel ligado à VCM]. Porque a saúde já é mais limitada à saúde mesmo, né? Não é assim... Porque aí já seriam outros órgãos. Seria a Delegacia da Mulher, o Conselho Tutelar. (Enfermeira)

Essa abordagem do assunto, porém, não significa que a violência mantenha-se afastada dos serviços de saúde. As mulheres que a sofrem buscam atendimento nas unidades. A assistência recebida via de regra se resume ao tratamento de sintomas e lesões. A causa do problema permanece negligenciada, ocasionando a persistência de danos físicos, psicológicos e sociais e a busca reiterada dos serviços ${ }^{4}$.

É, é pedir os exames, tratar... (Médica)

Algumas vêm com traumas cranianos, com cortes, com hematomas. Violência física mesmo; mental [...] a gente não sabe diferenciar. (Enfermeira) 
Principalmente por eu ser psiquiatra, eu sempre tento ir pelo lado dos sintomas que a pessoa está sentindo. Tento, né, fazer com que ela traga esse problema. Você, no caso, pode estar medicando a pessoa, às vezes, se é necessário, com um antidepressivo, um ansiolítico. (Médico)

Outra possibilidade é a de que a situação seja reconhecida como violência, mas não como objeto da intervenção em saúde. Dessa forma, em muitos dos casos em que o profissional optou por intervir, vê sua ação como pessoal e não profissional. Não reconhecendo nenhuma qualidade técnico-científica nesse agir, os profissionais consideram tais ações deslocadas e ineficazes, ainda que os tenham ocupado. Ao mesmo tempo, não lhes parecem revestidas da responsabilidade profissional, que sempre acompanha a intervenção que é parte de seu repertório assistencial. Sua atuação é vista não como uma orientação do tipo técnico-científica, tal qual poderia vir a ser em tecnologias apropriadas a essas situações, mas como um conselho pessoal ou, até mesmo, uma demonstração afetiva.

Como profissional, bom... Vamos dizer como mulher, nem como profissional... Se você pudesse, você dava uns cascudos no marido dela, certo? Ou sei lá quem... quem fez ela sofrer essa violência. E você não pode, quer dizer, você tem que estar ali para ajudar nas necessidades dela, para tentar fazer com que tudo isso amenize para ela. (Médica)

As mulheres não procuram ajuda no nível profissional, mas pessoal: de mulher para mulher, dando um esclarecimento que está nas nossas condições. (Enfermeira)

As entrevistadas do sexo feminino parecem sensibilizar-se mais com a questão, enfatizando a solidariedade e a compaixão entre mulheres na esfera da pessoalidade. Resultado similar foi encontrado em estudo mexicano ${ }^{9}$, apontando uma identidade de gênero.

No entanto, de forma geral, os entrevistados afirmam que as mulheres são responsáveis pela situação que vivem, fruto de suas escolhas pessoais. Julgam muitas vezes equivocados os valores que informam essas escolhas, imprimindo uma forte carga moral nessas opiniões.

Olha, eu sinto que é uma covardia muito grande, mas que a mulher é muito cúmplice de tudo o que acontece, sabe? Ela também não tem aquela iniciativa de sair daquele papel de subalterna. A maioria das mulheres, eu acho, que elas ainda veem o marido com direitos de agredi-las. E têm vergonha também de falar quando isso acontece. (Médica)
Às vezes, eu tenho vontade de dizer para as pessoas a realidade: que ela passa por aquilo porque ela quer passar. Mas aí eu já não digo, porque ela já está acabada, arrasada, maltratada, e a gente ainda dizer para ela a verdade... Porque essa seria a verdade. (Enfermeira)

A violência é também um problema que os profissionais remetem às esferas sociais e econômicas: o acesso precário à educação, o desemprego generalizado. Ou a relacionam a comportamentos como o abuso de álcool e drogas que também remetem à pobreza ou baixa escolarização. As soluções são, portanto, remetidas a aspectos sociais e culturais, dentro de um ideal genérico de sociedade cuja construção está sempre além de qualquer possibilidade do campo da saúde e é muito vezes atribuído à esfera governamental.

O que está faltando para a população para acabar com a violência é muito mais profundo: desemprego, falta de educação, guerra, falta de base. Isso é o que nós temos e o que falta para essa população, para eles conseguirem ter um pouco mais de equilíbrio emocional e, com esse equilíbrio, conseguir lidar com brigas e discussões, com conflitos de relacionamento e, com isso, melhorar. Por que a saúde vai mexer com isso? Inicialmente, eu pensaria, já que é um distúrbio emocional, momentâneo, não distúrbio de doença, mas emocional, então a gente poderia mexer na saúde. Mas teria outras áreas além da nossa, no caso, o governo, que poderia agir para conseguir evitar isso aí. (Médica)

Social! É um problema da educação, principalmente da educação. Muita falta de informação; isso gera violência. A violência na casa do cidadão é problema de quê? Dinheiro, trabalho, muitas vezes vício, alcoolismo que está aí, as drogas. Então é um problema social! (Enfermeira)

Diante do exposto, não surpreende que o trabalho direto com a questão da violência provoque, entre os entrevistados, sentimentos bastante negativos, como impotência, frustração, revolta, indignação, inconformismo, medo, angústia, tristeza, estresse e solidão.

Às vezes, a gente se acha meio impotente, porque tem coisa que a gente não resolve, que a gente tem que fingir que não viu. (Enfermeira)

Em síntese, a violência assume uma posição marginal como objeto de intervenção em saúde e, dessa forma, não é incorporada na construção do trabalho em saúde. É remetida a campos distintos de intervenção, tomada como cadeia de causalidade que escapa ao espectro da saúde. 


\section{Discussão}

\section{A racionalidade biomédica na abordagem de temas médico-sociais}

Tanto os dados quantitativos como os qualitativos reafirmam a invisibilidade da violência contra mulheres na assistência à saúde, reiterando a literatura sobre o tema. Neste estudo, exploramos adicionalmente obstáculos de ordem tecnológica à incorporação da violência doméstica no atendimento cotidiano em saúde. Ao buscarmos os significados que os profissionais detêm acerca de seus trabalhos, procuramos contrastar o quanto a violência seria dotada de mesmos sentidos. Contudo, sua natureza de objeto médicosocial não encontrou identificação na racionalidade biomédica de intervenção, hegemônica nas profissões em saúde. Consideramos residirem também aí as dificuldades dos profissionais em lidarem com a violência, ocasionando sua invisibilidade nos serviços, o que poder-se-ia estender a outras temáticas dessa mesma natureza.

O pensamento e o agir em saúde são pautados nos pressupostos e na organização da clínica médica, que privilegia em sua abordagem as lesões ou as disfunções orgânicas. Os eventos não reconhecidos como tal permanecem excluídos da formulação diagnóstica e terapêutica: seriam apenas suporte para as conclusões fisiopatológicas que irão balizar o projeto de intervenção, sem constituírem parte deste ${ }^{22}$. O olhar, portanto, dirige-se ao corpo individualizado e apartado da sua existência psíquica, das especificidades de sua inserção social e das significações culturais atribuídas à experiência do indivíduo no mundo. $\mathrm{O}$ sofrimento que ultrapassa a dimensão fisiopatológica não encontra sentido tecnológico assimilável e compatível ao dos objetos biomédicos e dificilmente conseguirá integrar-se na proposta de intervenção. Há, então, recusa do problema, a qual pode ser também de ordem pessoal ou moral, mas, será, ainda, de natureza tecnológica e diretamente informada pela racionalidade e preceitos técnico-científicos adotados.

Para os casos em que lidar com a situação de violência se impõe, quer por solidariedade, quer por compromisso ético, as respostas permanecem frequentemente ancoradas em uma mobilização afetiva do profissional. Nesse contexto, a exigência de imparcialidade e neutralidade de julgamento - que caracteriza a valorizada dimensão técnico-científica da assistência em saúde traz impasses para os profissionais na estruturação do seu trabalho, comprometendo uma fa- ceta distinta da responsabilidade profissional, o que explicaria nos achados desta pesquisa a presença de intervenção desacompanhada do compromisso profissional para com o caso efetivamente acolhido.

O plano intersubjetivo, confundido muitas vezes com o plano estritamente pessoal, refletiria, na percepção dos entrevistados, a ausência da neutralidade e da objetividade profissionais. A possibilidade desse tipo de agir está dada, segundo os profissionais, pelo estabelecimento de uma relação pessoal de confiança entre eles e as usuárias. O que os profissionais não percebem e, portanto, não tematizam é que a relação de confiança não precisa adquirir necessariamente esse caráter pessoal, pois é também nos referenciais da atividade de consulta a base do exercício intersubjetivo de caráter profissional, legitimando a intervenção $0^{17}$. Negligenciada essa qualidade integradora da dimensão intersubjetiva com o técnico-científico, e valorizando apenas os procedimentos deste último tipo, restaria ao profissional o entendimento de que julga e decide pelas crenças, aversões ou identificações pessoais. Com valores de fato independentes e não articulados ao saber médico, portanto. Disso resulta a percepção de que as terapêuticas ou orientações que pratica relativamente à situação de violência também seriam de bases estritamente pessoais.

Agregue-se a isso o fato de que o modelo profissional instiga em seu agente um pragmatismo e uma ética da salvação ${ }^{23}$, pressupostos da exigência de sempre agir em relação ao paciente, estimulando alguma resposta por parte do profissional. Assim, mesmo desvalorizada, essa resposta acaba por ser, quando ocorre, o único recurso reconhecido. Se é necessário sempre fazer algo, a ação de cunho pessoal preenche o vazio tecnológico deixado pela ausência de um projeto de intervenção bem definido. Muitas vezes os profissionais realizam e validam como sua prática um aconselhamento moral. Os que se recusam a participar nessa direção constroem a representação oposta: as orientações seriam sempre conselho pessoal, então deixando de reconhecer, especialmente os médicos, a possibilidade de qualquer aconselhamento como tecnologia válida, mesmo quando instruído por saberes científicos.

Em particular para os médicos, essa representação é potencializada pelo individualismo ontológico da prática médica, que coloca a decisão profissional como objeto (quase sempre exclusivo) de julgamento individual ${ }^{17,24}$. Um isolamento de prática que se faria necessário exatamente pela complexidade tecnológica do ato mé- 
dico, já que seria este o profissional quem "conduz o caso", o que o tornaria proprietário do paciente. Daí não buscarem soluções em outras experiências, quer de outros profissionais da saúde, quer de outros setores ou instituições assistenciais: não encaminham e, em sua maioria, desconhecem serviços especializados no atendimento a mulheres em situação de violência.

Reforçando todos esses obstáculos para visibilizar a violência, os caminhos trilhados pelas mulheres na busca de uma solução ou a frequente decisão de permanecer vivendo com o agressor desafiam o sentido da proposta assistencial mais convencional. Dependente dos valores e atitudes da própria mulher em situação de violência, determinadas propostas de intervenção são recusadas, o que gera no profissional o sentimento de ineficácia ou falta de controle sobre os resultados da sua intervenção ${ }^{11}$. Isto também valida a invisibilidade dos casos, como situação preferível. Além disso, ao remeter, de forma exclusiva, a violência contra mulheres à esfera dos problemas sociais, como combate à pobreza, ao desemprego ou ao consumo de álcool ou drogas, os profissionais delimitam um campo de intervenção para a saúde em que nenhuma experiência pedagógica ou intenção educativa poderia se inscrever como um projeto assistencial legítimo, reforçando um caráter ocasional e improvisado da intervenção nos casos de violência.

\section{Considerações finais}

A presente pesquisa sugere que, ao menos até 2002, as iniciativas em políticas públicas para o atendimento de casos de violência contra mulheres nos serviços de saúde na área metropolitana de São Paulo não provocaram no plano do cotidiano dos profissionais impactos significativos. Não houve reconhecimento desse agravo como um objeto do trabalho em saúde, o que se mostra dependente da vontade ético-política do profissi- onal em intervir e do reconhecimento de um agir técnico pertinente. Nenhuma dessas duas condições está satisfeita para os profissionais entrevistados: o agir técnico encontra-se substituído pelo domínio do pessoal, e a vontade ético-política de intervir fica borrada pela imagem de usuários incapazes, desprovidos do repertório mínimo para compreensão do sistema de saúde e das orientações transmitidas por seus profissionais.

Da perspectiva da intervenção, as propostas devem ser bastante inovadoras, não bastando uma incorporação de protocolos tradicionais, em guias tecnicistas da ação. Isto obstaculiza as transformações paradigmáticas necessárias à inclusão de temáticas médico-sociais na assistência à saúde. A proposta de um protocolo implica habilidade diagnóstica que alcance boa especificidade e sensibilidade, além da oferta de uma resposta adequada ao problema detectado que alie elementos técnicos com intersubjetividade e interação profissional-paciente, permitindo o desenvolvimento de um olhar mais sensível e informado quanto a questões médico-sociais. E isto depende da aquisição por parte dos profissionais de novos conhecimentos e habilidades, com redefinição cultural do escopo de sua ação e da própria reorganização dos serviços, com a inclusão da atenção a situações de violência também como preocupação gerencial dos serviços.

Em termos profissionais, seriam apropriados para tanto, já na formação técnica ou na universitária, esforços direcionados ao entendimento da dinâmica de problemas sociais mais complexos, além da construção de modelos colaborativos de intervenção com outros ramos profissionais e setores de assistência. É nesse processo de reconstrução que se encontram as possibilidades de sensibilização a temas médico-sociais e o aprendizado de formas de intervenção mais apropriadas aos casos. Assim, a inserção da temática da violência contra mulheres deve ser realizada não só na esfera assistencial, mas também na formação dos profissionais da saúde.

\section{Colaboradores}

LB Kiss e LB Schraiber participaram igualmente de todas as etapas da elaboração do artigo. 


\section{Referências}

1. Farah MFS. Gênero e políticas públicas. Estudos Feministas 2004; 12(1):47-71.

2. Barsted LAL. Violência contra a mulher e cidadania: uma avaliação das políticas públicas. Cadernos Cepia 1994; 1(1):9-25.

3. Krug EG, Dahlber LL, Mercy JA, Zwi AB, Lozano $\mathrm{R}$. WHO report on violence and health. Genebra: World Health Organization; 2002.

4. Schraiber LB, d'Oliveira AFPL, Falcão MTC, Figueiredo WS. Violência dói e não é direito: a violência contra a mulher, a saúde e os direitos humanos. São Paulo: Ed. Unesp; 2005.

5. Cohen S, De Vos E, Newberg E. Barriers to physicians identification and treatment of family violence: lesson from five communities. Acad Med 1997; 72(Suppl.1):S19-S25.

6. Ferris LE, Norton P, Dunn EV, Gort EH. Clinical factors affecting physician's management and decisions in cases of female partner abuse. Fam Med 1999; 31(6):415-425.

7. Garimella RN, Plichta SB, Houseman C, Garzon L. How physicians feel about assisting female victims of intimate partner violence. Acad Med 2002; 77(12Pt1):1262-1265.

8. Gutmanis I, Beynon C, Tutty L, Wathen CN, MacMillan HL. Factors influencing identification of and response to intimate partner violence: a survey of physician and nurses. BMC Public Health 2007; 7:12.

9. Herrera C, Agoff C. Dilemas del personal médico ante la violencia de pareja en Mexico. Cad Saude Publica 2006; 22(11):2349-2357.

10. Roelens K, Verstraelen K, Van Egmond K, Temmernan M. A knowledge, attitude and practice survey among obstetrician-gynecologists on intimate partner violence in Flanders, Belgium. BMC Public Health 2006; 6:238.

11. Sugg NK, Inui T. Primary care physician's response to domestic violence. JAMA 1992; 267(23):3157-3160.

12. Tower M. Intimate partner violence and the health care response: a postmodern critique. Health Care Women In 2007; 28(5):438-452.

13. Waalen J, Goodwin MM, Spitz AM, Petersen R, Saltzman LE. Screening for intimate partner violence by health care providers: barriers and interventions. Am J Prev Med 2000; 19(4):230-237.

14. Zink T, Regan S, Goldenhar L, Pabst S, Rinto B. Intimate partner violence: what are physicians' perceptions? J Am Board Fam Pract 2004; 17(5):332-340.
15. Luz MT. Racionalidades médicas e bioéticas. In Palácios M, Martins A, Pergoraro O, organizadores. Ética, ciência e saúde: desafios da bioética. Petrópolis: Vozes; 2002. p. 76-85.

16. Mendes-Gonçalves RB. Medicina e historia: raíces sociales del trabajo médico. México: Siglo Veintiuno Editores; 1984

17. Schraiber LB. O médico e seu trabalho: limites da liberdade. São Paulo: Hucitec; 1993.

18. Schraiber LB, d'Oliveira AFPL, Couto MT, Hanada H, Kiss LB, Durand JG, Puccia MI, Andrade MC. Violência contra mulheres entre usuárias de servicos públicos de saúde da Grande São Paulo. Rev Saude Publica 2007; 41(3):359-367.

19. Garcia-Moreno C, Jansen HAFM, Ellsberg L, Watts C. Prevalence of intimate partner violence: findings from the WHO multi-country study on women's health and domestic violence. Lancet 2006; 368:12601269.

20. Bardin L. Análise de conteúdo. Lisboa: Edições 70; 1988.

21. Ângulo-Tuesta AJ. Gênero e violência no âmbito doméstico: a perspectiva dos profissionais de saúde [dissertação]. Rio de Janeiro: Escola Nacional de Saúde Pública Sergio Arouca, Fundação Oswaldo Cruz; 1997.

22. Ayres JRCM. Epidemiologia e emancipação. São Paulo: Hucitec; Rio de Janeiro: Abrasco; 2002.

23. Good BJ. Medicine, rationality, and experience: an anthropological perspective. Cambridge: University Press; 1990.

24. Atkinson P. Medical talk and medical work. Londres: Sage Publications; 1995.

Artigo apresentado em 23/01/2008

Aprovado em 27/06/2008

Versão final apresentada em 06/08/2008 